\title{
"ISTO É COISA PARA 'MULHERES": GÊNERO E DESIGN NO DESENVOLVIMENTO DE PRODUTOS PARA A SOCIEDADE
}

\author{
Maristela Mitsuko Ono' \\ Marilia Gomes de Carvalho"
}

\begin{abstract}
RESUMO
A partir de estudos sobre a questão de gênero e estudos de caso, realizados no setor industrial de eletrodomésticos, este artigo discute a relação entre gênero e design, a partir da análise do desenvolvimento de produtos industrializados, com base em pesquisas e conceitos que focalizam o público feminino e exploram o estereótipo social de gênero do "isto é coisa para 'mulheres'". Salienta a necessidade de uma maior ênfase na abordagem da questão da pluralidade de gêneros na gestão do desenvolvimento de produtos industrializados, de modo que estes acompanhem a dinâmica das transformações sociais e contribuam para um desenvolvimento mais equilibrado das relações de gênero, que depende, dentre outros fatores, de uma participação cooperativa de pessoas de diferentes gêneros na execução das atividades do cotidiano na sociedade.
\end{abstract}

Palavras-chave: Design. Desenvolvimento de Produto. Gênero. Sociedade.

\section{INTRODUÇÃO}

O principal objetivo deste artigo é trazer uma contribuição aos estudos de design, no que tange ao desenvolvimento de produtos, envolvendo questões de relações de gênero na sociedade.

Baseia-se em estudos sobre gênero, que vêm sendo desenvolvidos por Carvalho $^{1}$, e em estudos de cunho exploratório, extensivos às pesquisas sobre a questão da diversidade cultural no âmbito do design industrial, realizados por Ono (1999; 2004).

Várias abordagens conceituais têm sido desenvolvidas, com o objetivo de um melhor entendimento sobre as questões de gênero na sociedade. De um modo geral, há uma convergência em relação ao fato de que se tem considerado na sociedade diferenças entre "homens" e "mulheres", desde que estes nascem, e isto tem influenciado as noções que se tem sobre "gênero", bem como a formação de valores, organizações, modos relacionais e práticas entre diferentes gêneros na sociedade, nos vários contextos micro e macro. Estes abrangem desde a esfera privada, do indivíduo e da família, até a pública, onde se situam os diversos grupos sociais e as instituições de ensino, religiosas, comerciais, governamentais, dentre outras. ${ }^{2}$

1 Graduada em Arquitetura e Urbanismo (UFPR); Industrial Design Training Course (JIDPO, Japão); Doutora (USP); Professora do Programa de Pós-graduação em Tecnologia e do Departamento Acadêmico de Desenho Industrial do CEFET-PR.

E-mail: ono@ppgte.cefetpr.br

" Graduada em Antropologia e Sociologia (UFPR); Doutora (USP); Pós-doutorado em Multiculturalismo (Université de Technologie de Compiègne, França); Professora do Programa de Pós-graduação em Tecnologia do Grupo de Estudos e Pesquisas em Relações de Genero e Tecnologia do CEFET-PR.

E-mail: carvalho@ppgte.cefetpr.br 
Notadamente a partir da segunda metade do século XX, as "mulheres" conseguiram importantes avanços na luta por seus direitos e atuação na sociedade, inclusive em termos de força de trabalho, onde sua participação cresceu substancialmente nas últimas décadas ${ }^{3}$, salientando-se a necessidade de uma reinterpretação e reorganização das relações de gênero nas esferas da vida pública e privada. Não obstante, a existência de barreiras sociais, culturais, econômicas e políticas, dentre outras, sedimentadas e incrustadas na trajetória das mesmas, têm dificultado o desenvolvimento de organizações e práticas mais cooperativas nas relações de gênero, que requerem uma divisão mais equilibrada das responsabilidades e tarefas entre indivíduos de diferentes gêneros, tanto na esfera da vida pública, quanto privada.

O patriarcalismo - um dos modelos sobre os quais se fundou a sociedade contemporânea e que se baseia na relação binária e hierárquica entre "homem" e "mulher" - os quais assumem papéis dicotomizados e predeterminados, sendo a "mulher" subordinada ao "homem" - tem sofrido críticas e retrações consideráveis ao longo da história. No entanto, ressalvando-se as diferenças sócioculturais entre sociedades de períodos históricos diferentes e distantes, verifica-se a reprodução de alguns aspectos de tal sistema em várias instâncias sociais, culturais, políticas e econômicas, públicas e privadas, o que tem trazido implicações, diretas e indiretas, à formação da identidade de indivíduos de diferentes gêneros, bem como às relações entre os mesmos na sociedade. De acordo com Bourdieu (1999), a dominação masculina vem acompanhando o desenvolvimento da humanidade ao longo do tempo sem nunca ter sido substancialmente superada nem mesmo nas sociedades modernas, tidas como mais democráticas, onde a igualdade de direitos é princípio fundamental.

Os movimentos feministas têm desempenhado um papel importante nas lutas pela defesa dos direitos humanos relacionados às questões de gênero e pela melhoria das relações entre indivíduos e grupos sociais na sociedade. Entretanto, problemas como aqueles relacionados às influências das estratégias de desenvolvimento de produtos industrializados - na reprodução de modos relacionais de gênero patriarcais, hierárquicos e excludentes na sociedade - merecem uma maior atenção por parte da gestão do feminismo, cujo papel é relevante na reivindicação e desenvolvimento de uma política de comunicação que promova relações de gênero equilibradas e cooperativas, no que tange à participação dos diferentes gêneros na prática das atividades do cotidiano na sociedade.

De cunho interpretativista e abordagem qualitativa, este artigo tece uma crítica à política de desenvolvimento de produtos industrializados, que explora (implícita ou explicitamente) o estereótipo do "isto é coisa para mulheres", fundamentado na visão binária de "homem" e "mulher" e na dicotomia de papéis sociais a estes atribuídos, referindo-se, neste caso, àqueles tradicionalmente estabelecidos como sendo, por predestinação, "afins às

3 No Brasil, por exemplo, o índice participação das mulheres, no total da população economicamente ativa, passou de $12,65 \%$ para $32,59 \%$, no período de 1950 a 2000, segundo o Labour Statistics of the ILO - Bureau of Statistics (1950-2000). 
'mulheres', a quem cabe o seu desempenho" na sociedade. Este é o caso, por exemplo, do trabalho doméstico, que inclui as atividades de cozinhar, limpar a casa, lavar e passar a roupa, cuidar dos filhos, dentre outras.

Tal política de desenvolvimento de produtos tem contribuído para reproduzir valores, padrões e práticas, nas esferas da vida pública e privada, que revelam relações de gênero dicotômicas, hierárquicas, perversas e excludentes. Dicotômicas, porque se baseiam em uma visão reducionista, genérica e binária de "homem" e "mulher", com a atribuição de papéis específicos para cada um destes. Hierárquicas, porque se fundamentam na desigualdade, em termos de grau de poder entre a "mulher" e o "homem", sendo que a posição deste último continua prevalecendo. Perversas, porque sobrecarregam a "mulher" de múltiplas funções, com a responsabilidade de arcar com o trabalho doméstico, além de, em muitos casos, acumular outras funções, na esfera pública e privada. E excludentes, porque criam barreiras e preconceitos, em relação à participação de outros gêneros em atividades rotuladas como sendo, por predestinação, “afins às 'mulheres', a quem cabe o seu desempenho" na sociedade.

Este trabalho baseia-se em: 1) estudos de caso, desenvolvidos por Ono (1999; 2004) junto a empresas do setor industrial de eletrodomésticos (nas áreas de design); 2) em pesquisa de material de publicidade e propaganda de eletrodomésticos portáteis ${ }^{4}$ (da Walita ${ }^{5}$ e Moulinex ${ }^{6}$ ) e de linha branca ${ }^{7}$ (da Brastemp ${ }^{8}$; General Electric ${ }^{9}$; Mueller $^{10}$ e Electrolux ${ }^{11}$ ), focalizando aqueles comercializados no Brasil, em meados do século $X X$ (quando se intensificou o consumo de eletrodomésticos na sociedade), e no período mais recente, do final do século $X X$ e início do século $X X I$; e 3) em estudos sobre gênero, desenvolvidos por Carvalho.

Focaliza produtos eletrodomésticos, na medida em que os mesmos têm assumido um papel importante no desenvolvimento do trabalho doméstico, que faz parte das atividades da família, um núcleo social bastante representativo, em termos das relações de gênero na sociedade.

Este estudo parte do entendimento de que as noções de "homem" e "mulher" fundamentam-se em juízos de valor (que são variáveis e

\footnotetext{
${ }^{4}$ Pertencem à linha de portáteis, por exemplo, os liquidificadores, as batedeiras de bolo, os ferros de passar roupa, dentre outros produtos.

${ }^{5}$ A Eletro-Indústria Walita era uma empresa originalmente brasileira, que iniciou suas atividades na década de 1940 e se destacou na produção e comercialização de eletrodomésticos portáteis, sendo posteriormente adquirida, em 1971, pela multinacional holandesa Philips, que continua comercializando produtos com a marca Walita no Brasil.

6 A Moulinex é uma multinacional de origem francesa.

7 Pertencem à linha branca, por exemplo, os refrigeradores, freezers, fogões, lavadoras de roupa, dentre outros produtos.

8 A Brastemp era uma empresa brasileira pertencente ao grupo Brasmotor, e, atualmente, é uma marca de propriedade da Multibrás (que também é proprietária da marca Consul), subsidiária da multinacional norte-americana Whirlpool.

9 A General Electric é uma multinacional de origem norte-americana.

10 Mueller é uma empresa brasileira.

11 A Electrolux do Brasil é uma subsidiária da multinacional, de origem sueca, Electrolux.
} 
questionáveis) e em uma perspectiva reducionista e binária dos seres humanos. Conforme argumenta Joan Scott (1995, p. 93):

...'homem' e 'mulher' são, ao mesmo tempo, categorias vazias e transbordantes. Vazias, porque não têm nenhum significado último, transcendente. Transbordantes, porque mesmo quando parecem estar fixadas, ainda contêm dentro delas definições alternativas, negadas ou suprimidas.

As noções e relações de gênero, por sua vez, vinculam-se tanto a conceitos relacionados à sexualidade, quanto a representações, organizações e práticas de poder na sociedade. Abarcam significados complexos, dinâmicos e variáveis para cada indivíduo e sociedade, não podendo, portanto, ser analisadas a partir de um ponto de vista geral, universal e meramente biológico, desvinculado dos contextos e das inter-relações históricas, sociais, culturais, econômicas e políticas.

Entende-se, de acordo com Françoise Thébaud (1998, p. 113), que:

O gênero é, em certo sentido, o "sexo social" ou a diferença de sexos construída socialmente, conjunto dinâmico de práticas e representações, com atividades e funções designadas, atributos psicológicos, um sistema de crenças. Percebe-se o sexo, assim, como invariável, enquanto que o gểnero é variável no tempo e espaço, e a masculinidade ou a feminilidade, ser homem ou mulher, ou ser considerado como tal, não tem o mesmo significado em todas as épocas, nem em todas as culturas.

Salienta-se na organização e na prática de atividades do cotidiano da sociedade, como o trabalho doméstico, por exemplo, que qualquer que seja a diferenciação percebida, atribuída, representada e institucionalizada, no que tange à questão de gênero, a mesma, por si só, não justifica o desenvolvimento de nenhum tipo de hierarquização, desigualdade, preconceito e exclusão nas relações humanas.

\section{Artefatos e design: referências e mediadores nas relações sociais}

Desde que o ser humano começou a interferir no espaço natural, através da criação de seus primeiros artefatos ${ }^{12}$, estes passaram a interagir e a participar na formação de si mesmo, tornando-se um referencial para a sua própria existência. Assim, a natureza, o desenvolvimento e a cultura do ser humano configuram-se como processos inseparáveis, conforme sustenta Geertz (1989; 1996), dentre outros. E é desta relação fundamental que emergem a construção de símbolos, a linguagem, a comunicação, as relações e as práticas dos indivíduos e grupos sociais.

Vivemos envolvidos por artefatos que nos são disponíveis e que ajudam a moldar nossas vidas, constituindo-se signos simbólicos, que trazem significados às relações sociais e referenciais às identidades das pessoas.

12 Entende-se aqui como artefato "qualquer objeto produzido pelo homem" (DEVINNE et al, 1991, p. 130) 
O objeto, segundo Moles (1973, p. 199), é "um vetor de comunicações, no sentido sócio-cultural do termo: elemento de cultura, [o objeto] constitui a concretização de um grande número de ações do homem [...]". E, de acordo com Baudrillard (1993, p. 101-102), o objeto torna-se:

...suporte de uma rede de hábitos, ponto de cristalização de rotinas de comportamento. Inversamente, talvez não exista hábito que não gire ao redor de um objeto. Uns e outros envolvem-se inextricavelmente na existência cotidiana.

Os artefatos são, portanto, mediadores entre as pessoas, e entre estas e a cultura material ${ }^{13}$. Assumem funções (simbólicas, de uso e técnicas, dentre outras) e significados particulares para cada indivíduo e sociedade, refletindo e influenciando a construção de seus valores, referências, pensamentos e ações, e contribuindo para a satisfação de suas necessidades.

As funções dos artefatos encontram-se vinculadas não somente a características objetivas (ex.: peso, tamanho, material, desempenho, dentre outras), mas também ao contexto social e cultural, onde os mesmos se inserem, suprindo necessidades também subjetivas de indivíduos e grupos sociais. (DENIS, 1998)

O desenvolvimento do neocórtex no ser humano, segundo LaburtheTolra e Warnier (1997, p. 192), permitiu-Ihe um amplo grau de liberdade, individual e coletiva, para instaurar regras sociais de comportamento, invenções e descobertas de significações. Estas "significações", por sua vez, "repousam sobre um código" e "formam uma visão de mundo mais ou menos coerente, uma ideologia, que implica em um mínimo de classificação dos fenômenos e correspondência entre eles". E, assim como o contexto contribui para a significação dos objetos, qualquer variação do mesmo altera o significado destes.

Exemplos como os das panelas de arroz elétricas japonesas salientam as influências dos artefatos nas transformações das relações sociais, e vice e versa. A professora Akiko Takehara (1986), da Wako University do Japão, relata que, nesse país, avós, pais e crianças costumavam viver todos juntos, mas que, hoje em dia, jovens casais vivem separados dos pais e avós. E, mesmo que as duas gerações vivam juntas, necessitam de diferentes produtos, porque possuem diferentes gostos e exigências. Assim, com diferentes panelas de arroz para diferentes membros de uma mesma família, as pessoas perderam a oportunidade de comerem juntas.

A questão do gênero nas transformações sociais tem sido um dos fatores que têm influenciado significativamente o desenvolvimento de artefatos. Durante o século XVIII, por exemplo, quando as mulheres passaram a participar mais ativamente da vida social e cultural, sobretudo aquelas pertencentes à aristocracia e à burguesia, novos e variados tipos de móveis foram projetados exclusivamente para elas, tais como diversas chaises

13 Este estudo parte do entendimento da cultura material como o conjunto de artefatos produzidos e utilizados pelas culturas humanas ao longo do tempo, sendo que, para cada sociedade, os objetos assumem significados particulares, refletindo seus valores e referências culturais. 
ongues e espreguiçadeiras, conforme lembra Rybczynski (1999, p. 104). Além desses, no decorrer dos anos, vários outros artefatos foram sendo criados para facilitar o trabalho doméstico, como, por exemplo, as máquinas de lavar roupas e louças, que possibilitaram às pessoas poupar um tempo significativo para a realização de outras atividades de lazer e trabalho.

Entende-se, portanto, que os artefatos tanto são influenciados, quanto influenciam a reprodução, a transformação e a criação de valores, práticas e modos relacionais na sociedade. $E$, sob este prisma, salienta-se a responsabilidade que cabe àqueles que estão, de algum modo, envolvidos no desenvolvimento dos mesmos, considerando-se que afetam, direta e indiretamente, a vida dos indivíduos e o desenvolvimento da sociedade.

Este trabalho parte do conceito de design como "planejar, escolher, ou seja, receber e processar estímulos, selecionar modelos de pensamento e sistemas de valores", sendo, no que tange à sua dimensão cultural, "responsável pela relação entre sujeito e matéria", conforme sustenta Ezio Manzini (1993, p. 51). Entende-se ainda, segundo Klaus Krippendorff (1996, p. 156), que "design é dar sentido (a coisas)", e que, na esfera do design industrial, "... conceber uma máquina, um objeto de uso cotidiano, é estudar um produto, dentro de sua complexidade, enquanto elemento de um conjunto de objetos e enquanto sistema, e ele próprio em relação ao conjunto do ambiente material, econômico, social, cultural e biológico.", como observa Hélène Larroche (1980, p. 81). Deste modo, considera-se que os designers são co-responsáveis pelo desenvolvimento de produtos para a sociedade, bem como pelas implicações sociais, culturais, econômicas, ambientais, dentre outras, que trazem à mesma.

\section{Pesquisa e design de eletrodomésticos com foco nas "mulheres"}

Verifica-se, a partir de estudos de caso desenvolvidos no setor de eletrodomésticos, que a pesquisa de mercado e o design de produtos têm focalizado o público feminino.

Na década de 1990, desenvolveu-se, na Refripar ${ }^{14}$ - empresa brasileira de eletrodomésticos, proprietária da marca Prosdócimo - uma pesquisa sobre o perfil de consumidores, a partir de quadros de análise semiótica de mulheres brasileiras e de outros países da América do Sul. Tomou-se como base imagens coletadas das revistas nacionais mais compradas pelo público feminino da faixa etária entre 25 a 35 anos, observando-se também o conteúdo das reportagens, a fim de verificar em que as pessoas estariam interessadas, e posicionando as imagens de acordo com diferentes atitudes e perfis, enquadrados em características contraditórias, tais como, por exemplo: sentimental/racional, conservador/ousado, urbano/rural, erótico/ingênuo. (ver Figura 1)

14 A Refripar foi adquirida, em 1996, pela corporação multinacional Electrolux, passando a constituir a Electrolux do Brasil S.A. 


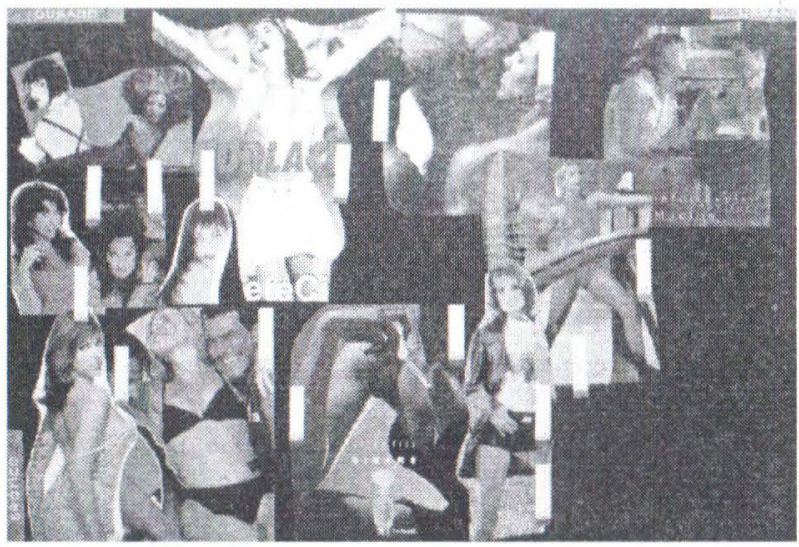

Figura 1

Detalhe de quadro de análise semiótica do perfil da mulher brasileira, desenvolvido por designers da Refripar

Fonte: Foto do arquivo de Maristela M. Ono

No caso das mulheres brasileiras, esta pesquisa identificou o predomínio de características de "sensualidade, sentimentalismo e erotismo". Poder-se-ia entender tal caracterização, em parte por sua natureza genérica, como sendo um estereótipo da mulher brasileira, assim como no caso da caracterização da mulher argentina ("sentimental e conservadora") e venezuelana ("mais racional e urbana"), que também foram pesquisadas. No entanto, segundo argumenta o atual Gerente Divisional de Design da Electrolux do Brasil/América do Sul, apesar desses estereótipos nem sempre representarem o que as mulheres realmente são, eles refletem o "desejo" que elas têm de ser assim, o que, em sua opinião, deve ser considerado no design de produtos. (ONO, 1999, p. 212)

A partir da análise das principais características do público consumidor feminino, relacionou-se às mesmas palavras-chave, tais como "dinamismo", "aconchego", "sentimento", "tecnologia", dentre outras, as quais, por sua vez, foram associadas a imagens de produtos diversos (ex.: automóveis, móveis, etc.), buscando-se identificar formas e linhas predominantes nos mesmos (ex.: formas arredondadas, associadas à afetividade, etc.).

Segundo o Coordenador das Células de Projeto do Centro de Design da Electrolux do Brasil ${ }^{15}$, este estudo tem ajudado a balizar o desenvolvimento de produtos da empresa, que passou a introduzir, a partir dos resultados das referidas análises, formas mais sensuais e mais suaves nos produtos direcionados ao mercado brasileiro. Tais características evidenciam-se ao se comparar eletrodomésticos brasileiros (ver Figura 2) com alemães, por

15 Entrevistado "C": entrevista. Curitiba, 1998. Entrevista concedida a Maristela Mitsuko Ono, em 14/jul. 2001. 
exemplo, os quais apresentam uma configuração geralmente mais rígida (ver Figura 3).

Também na Multibrás, proprietária das marcas Consul e Brastemp e subsidiária da corporação multinacional Whirlpool desde 1997, o desenvolvimento de eletrodomésticos têm focalizado o público feminino. Isto fica claro nas palavras do atual Gerente da Área de Refrigeração da empresa, em relação às referidas marcas:
. ... a marca Consul é uma marca mais passional. [...] O produto Consul ganha nome [...], tal o grau de intimidade que esses clusters de donas de casa têm com os produtos". [Já o produto Brastemp, não.] Ele é um produto com o qual, de maneira geral, quem tem o contato não é a dona de casa; é a empregada. A dona de casa que o tem é a moça solteira ou casada, mas de uma vida mais de vanguarda [... e que] não tem uma ligação muito sentimental com o produto. ${ }^{16}$

Tais conceitos têm se refletido no design dos eletrodomésticos, expressando-se na composição formal dos gabinetes e no grafismo, dentre outros aspectos, além de questões relacionadas ao uso e aos requisitos técnicos dos mesmos. Os produtos da Consul, por exemplo, possuem formas mais arredondadas e um grafismo mais colorido, mais alegórico, com mais elementos (ver Figura 4), que os da Brastemp, que são mais simples e sóbrios (ver Figura 2).
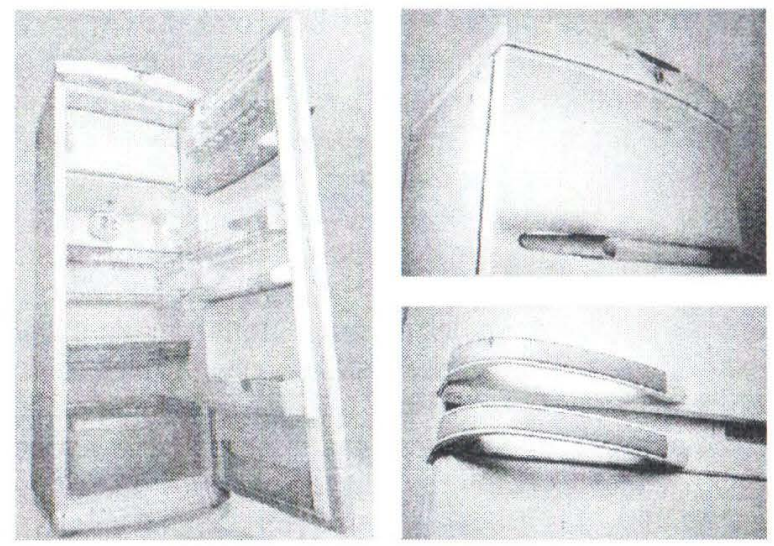

Figura 2

Refrigerador BRASTEMP e detalhes de puxadores (brasil, 2001)

Fontes: Catálogos da Brastemp, fev. 2001

16 Entrevistade "L": entrevista. Curitiba, 1998. Entrevista concedida a Maristela Mitsuko Ono, em 29/set. 1998. 

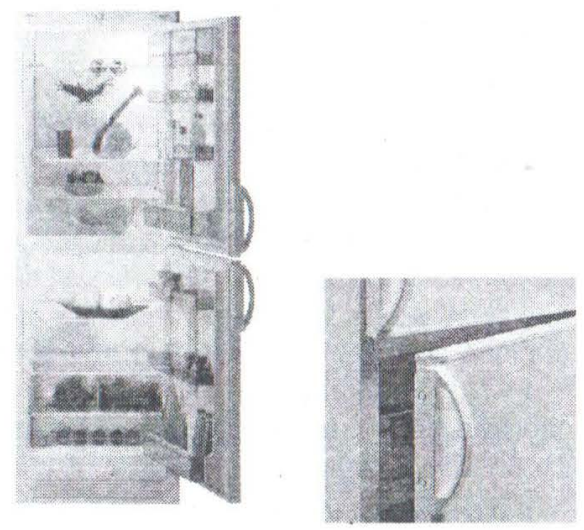

Figura 3

Refrigerador AEG E detalhe de puxadores (Alemanha, 1997)

Fonte: Catálogo da AEG, 1997/1998

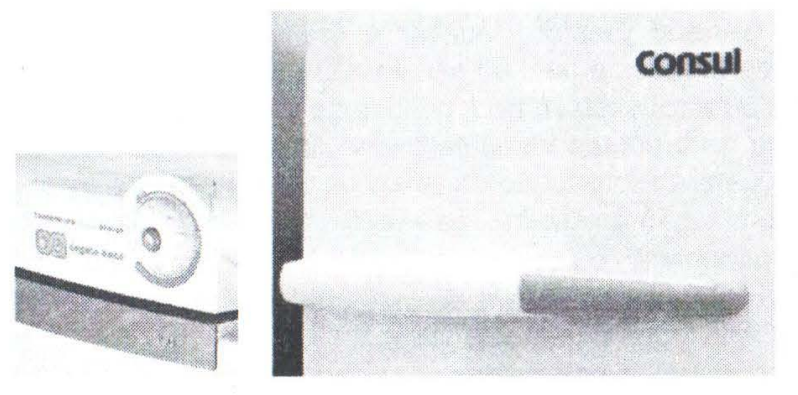

Figura 4

Termostato e puxador de refrigerador Consul (Brasil, 2002; 2004)

Fonte: Disponível em: <http://www.consul.com.br>.

Acesso em: 17 jul. 2004. Foto de Maristela Mitsuko Ono

Percebem-se, portanto, significativas implicações da questão de gênero no design de artefatos, salientando-se a importância de um maior aprofundamento dos estudos sobre a relação entre gênero e design na sociedade. 


\section{A comunicação para a promoção do consumo de Zeletrodomésticos com foco nas "mulheres"}

A comunicação tem sido um dos fatores determinantes no desenvolvimento da sociedade humana. Trata-se, segundo Coelho Netto (1980, p 209), de "uma atividade de representação visando transmitir um certo sentido". Ou, ainda, de acordo com Colin Cherry, consiste no "estabelecimento de uma unidade social entre seres humanos, pelo uso de signos de linguagem. [...] Comunicação não é resposta em si mesma, mas é essencialmente a relação que se éstabelece com a transmissão do estímulo e a evocação da resposta" (Cit. in: RABAÇA; BARBOSA, 1995, p. 151).

A comunicação traz em si representações e interpretações variáveis, que dependem tanto de fatores biológicos (visuais, auditivos, táteis, dentre outros), que permitem a percepção das mensagens, quanto dos contextos históricos, sociais e culturais, nos quais se insere.

Tem-se utilizado intensamente estratégias de "comunicação de massa"17, através de meios diversos, tais como os audiovisuais, gráficos, dentre outros, que exercem influências e trazem implicações tanto desejáveis, quanto indesejáveis, para os indivíduos e a sociedade, dependendo do conteúdo da mensagem utilizada e da interpretação que pessoas têm da mesma.

A partir de exemplos de material de publicidade e propaganda ${ }^{18}$ de eletrodomésticos portáteis (da Walita e Moulinex) e de linha branca (da Brastemp; General Electric; Mueller e Electrolux), divulgados em revistas brasileiras de meados e final do século XX, e início do século XXI, este artigo desenvolve uma reflexão sobre a política de comunicação voltada à promoção do consumo de produtos industrializados com foco nas "mulheres", que tem contribuído para a reprodução de relações de gênero que estabelecem como critério a dominação masculina, que fazem parte das raízes que demarcam o processo de formação da sociedade brasileira ${ }^{19} \mathrm{e}$ têm influenciado a complexa teia de inter-relações na esfera do imaginário, das organizações, relações e práticas de indivíduos e grupos sociais.

O recorte de tempo deste estudo - que focaliza o período de meados e final do século $X X$, e início do século $X X I$ - permite identificar certas

17 A "comunicação de massa", segundo Rabaça e Barbosa, consiste em uma comunicação "dirigida a um grande público (relativamente numeroso, heterogêneo e anônimo), por intermediários técnicos sustentados pela economia de mercado, e a partir de uma fonte organizada..." (1995, p. 163).

18

A "Publicidade e propaganda" desenvolvem um tipo de "comunicação persuasiva", destinada a "influenciar as opiniões, os sentimentos e as atitudes do público num determinado sentido". Tratase de um "processo de disseminar informações para fins ideológicos [...] ou para fins comerciais", conforme o entendimento de Rabaça e Barbosa (1995, p. 481).

19

No Brasil, a reforma do Código Civil de 1962 ampliou os direitos da mulher casada, mas esta continuou subordinada à chefia do marido na família, apesar de the ser atribuído o papel de "colaboradora" do mesmo (O Código Civil Brasileiro, em seu Capítulo II, artigo 233, afirma: "O marido é o chefe da sociedade conjugal, função que exerce com a colaboração da mulher, no interesse comum do casal e dos filhos"). 
transformações e reproduções de padrões na relação de gênero, na esfera da vida privada.

Na década de 1950, por exemplo, a Eletro-Indústria Walita S.A. utilizava estratégias de publicidade e propaganda para a promoção do consumo de seus eletrodomésticos portáteis, que demonstravam um direcionamento às "mulheres". Isto era feito de modo até explícito, seja através de imagens ou mesmo de texto escrito, como se pode observar nos exemplos apresentados a seguir (ver Figuras 5 a 8).

A comunicação refletia, neste período, a organização da família, na qual o "homem" era o chefe e provedor financeiro (há, em vista disto, vários exemplos, nos quais a comunicação se dirigia também àquele que geralmente comprava os produtos, ou seja, o "homem"), e a "mulher", "dona de casa", a responsável pelo trabalho doméstico (cozinhar, limpar a casa, lavar e passar as roupas, etc).

A imagem à esquerda da Figura 5 sugere uma família cuja autoridade está representada pelo pai, com a figura do "homem" (pai), seu chefe, sentado à cabeceira da mesa, os filhos também sentados à mesa e átentos ao mesmo, enquanto a "mulher" (mãe) se encontra de pé, servindo o marido.

A imagem à direita da Figura 5 associa a idéia de sonho de consumo da "mulher" (exemplificado com a batedeira de bolo) ao casamento.
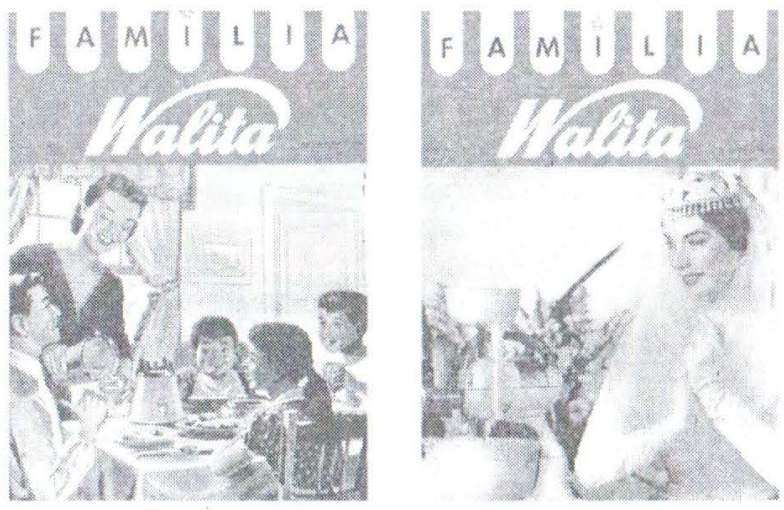

Figura 5

Capas de revista da walita (1956 e 1958)

Fontes: Revista Familia Walita, ano 1, $n^{\circ} 2$, jan. 1956;

Revista Familia Walita, ano 3, $n^{\circ}$ 15, jul./ago./set. 1958 
As imagens da Figura 6 também associam os eletrodomésticos ao sonho de consumo da "mulher", destacando a figura do "homem" (provedor financeiro da família) como aquele que compra o produto. $E$, na imagem à esquerda, os filhos se apresentam como espectadores no contexto da família.

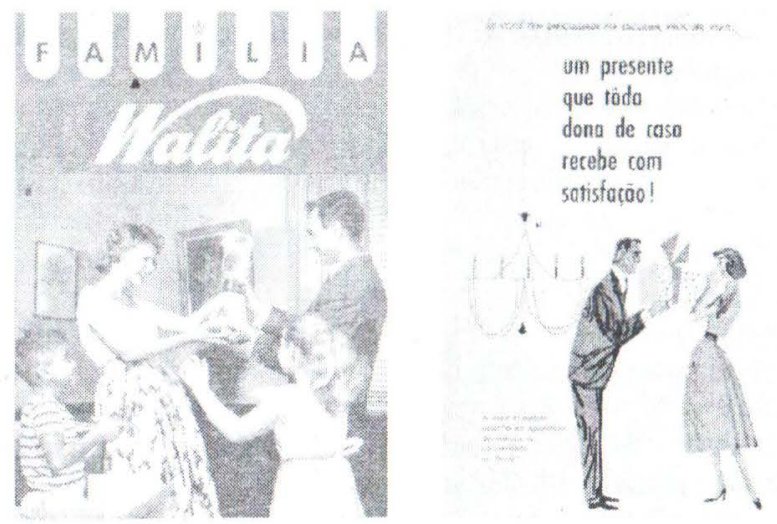

Figura 6

Capa de revista e de folder de

publicidade e propaganda da walita (1957)

Fonte: Bevista Família Walita, ano 2, n’ 9, mar./abr. 1957

Nos exemplos apresentados nas Figuras 7 e 8 associa-se a "mulher" ao papel de responsável pelo trabalho doméstico, e os eletrodomésticos como facilitadores na execução das tarefas.

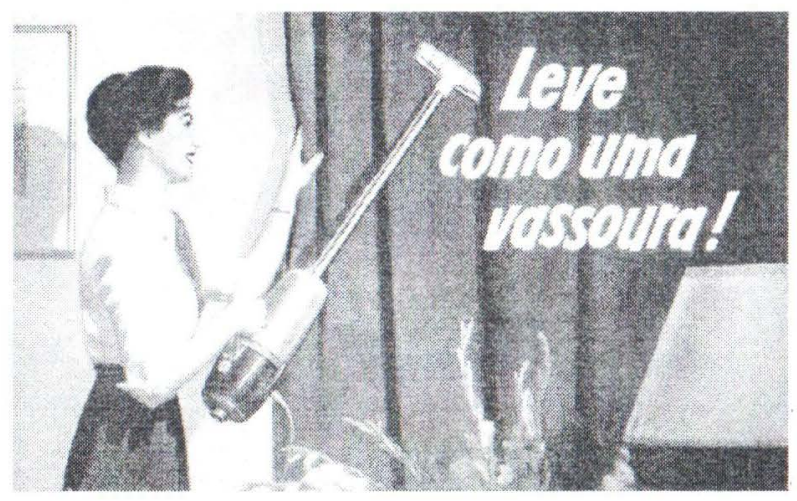

Figura 7

Publicidade e propaganda de aspirador de pó da walita (1958)

Fonte: Revista Família Walita, ano $3, n^{\circ} 14$, abr./maio/jun. 1958, contra-capa 


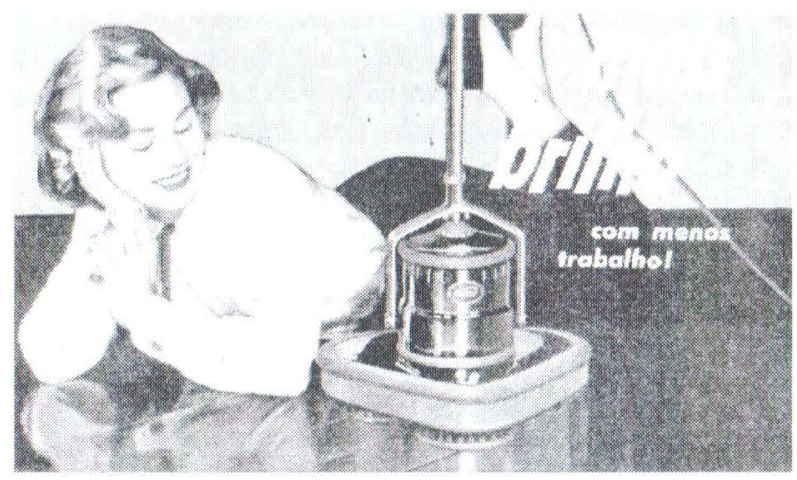

Figura 8

Publicidade e propaganda de enceradeira da walita (1958)

Fonte: Revista Familia Walita, ano $3, \mathrm{n}^{\mathrm{0}} 15$, jul./ago./set. 1958, contra-capa

Várias estratégias de comunicação foram utilizadas pela Walita, reforçando o direcionamento dos eletrodomésticos às "mulheres". Um exemplo foi a "Escolinha Walita", que desenvolvia cursos de culinária, através dos quais a empresa apresentava, orientava sobre o uso e promovia a venda de seus produtos (ver Figura 9).

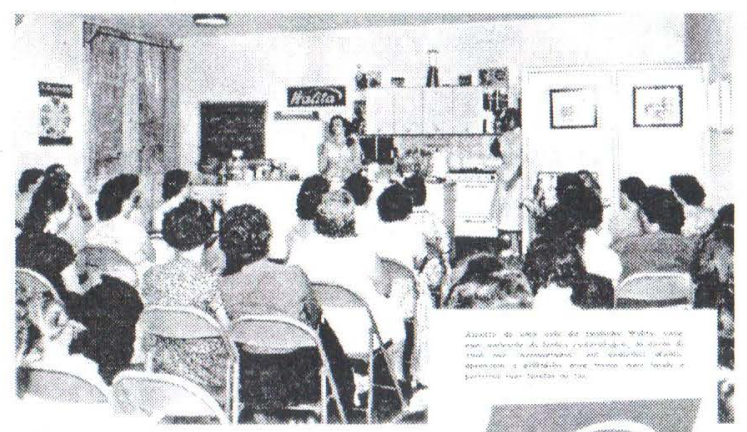

A ESCOLINHA

- aiude a render!

Figura 9

Curso da escolinha walita (1955)

Fonte: Revista Familia Walita, ano 1, nov. 1955, p.10 
Um texto, extraído da Revista Família Walita, de 1955 - referente à Escolinha Walita - ilustra o foco das estratégias de comunicação nas "mulheres", "donas de casa": "... num ambiente de franca camaradagem, as donas de casa são 'apresentadas' aos aparelhos Walita, onde aprendem a utilizá-los para tornar mais fáceis e perfeitas suas tarefas no lar"20.

A publicidade e propaganda de eletrodomésticos de linha branca como, por exemplo, a do fogão Brastemp Imperador, de 1960, também demonstra o foco no público femînino (ver Figura 10).

Exemplos de publicidade e propaganda mais recentes, da década de 1990 e início do século XXI, demonstram que as estratégias de comunicação dos eletrodomésticos em geral continuam focadas nas "mulheres", reproduzindo padrões tradicionais de relações de gênero entre o "homem" e a "mulher" (ver Figuras 11 a 14).

No exemplo ilustrado pela Figura 11, explicita-se textualmente o foco da comunicação nas "mulheres", associando-se os eletrodomésticos da empresa a produtos de beleza: "Os produtos de beleza que toda mulher gostaria de ter..." Reproduzem-se, assim, o estereótipo do "isto é coisa para mulheres" e associações da "mulher" a padrões de aparência visual.

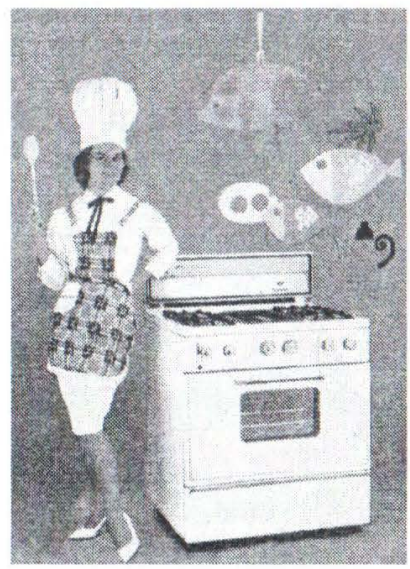

Figura 10

Publicidade e propaganda do fogão Brastemp "Imperador" (1960)

Fonte: Revista Seleções, 1960. In: TEIXEIRA, Francisco M. P. et al. O futuro sem fronteiras: a história dos primeiros 50 anos da Brasmotor.

São Paulo: Prêmio, 1996, p. 59 


\section{Moulinex}

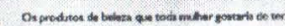

Producos de beleza.
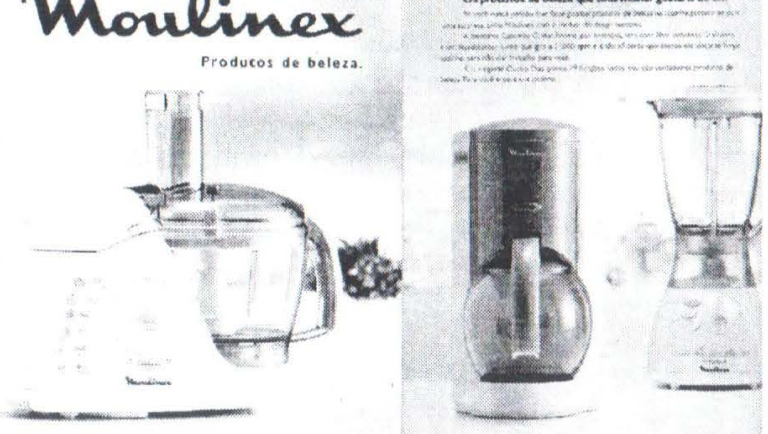

Figura 11

Publicidade e propaganda de eletrodomésticos portáteis da moulinex (1998)

Fonte: Bevista Claudia, ano 37, $n^{\circ} 12$, dez. 1998, p. 234-235

Algo similar ocorre no exemplo apresentado na Figura 12, onde se associa a imagem da mulher à beleza e à atividade de culinária, e estas, por sua vez, à linha de produtos (no caso, de fogões General Electric). Afirma-se, em seu texto principal: "A beleza e a culinária sempre estiveram muito próximas. A General Electric conseguiu unir as duas para sempre"22.

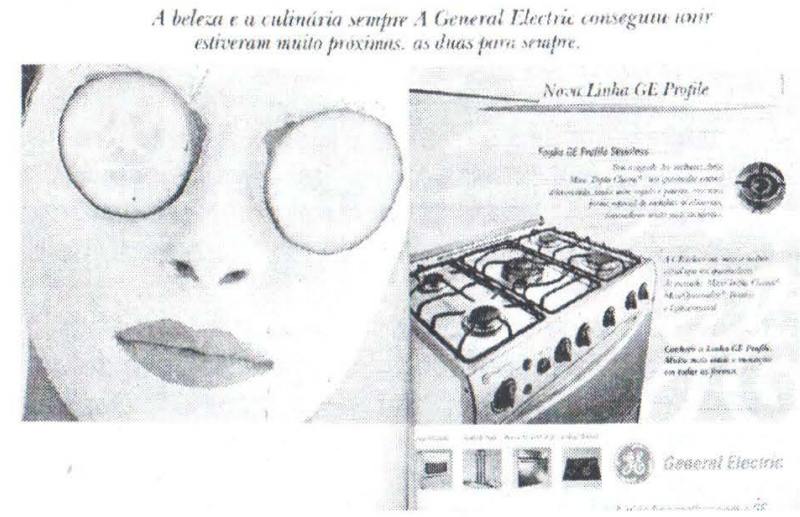

Figura 12

Publicidade e propaganda de fogão da general electric (2001) Fonte: Revista Claudia, ano 40, $n^{\circ} 10$, out. 2001, p. 284-285 
Essas imagens demonstram uma ênfase na tecnologia dos produtos, sugerindo a facilidade que a mesma proporciona às "mulheres" na execução do trabalho doméstico, poupando-lhes tempo para desenvolverem outras atividades, inclusive para cuidar de sua aparência.

Na Figura 13, o texto, referente aos fogões Mueller, deixa claro o foco da comunicação dos produtos nas "mulheres", "donas de casa": "Apresentados na versão quatro e seis boca, possuem exclusiva tecnologia de queima de alto rendimento que se traduz em economia para a dona de casa e boas vendas para o lojista"23.

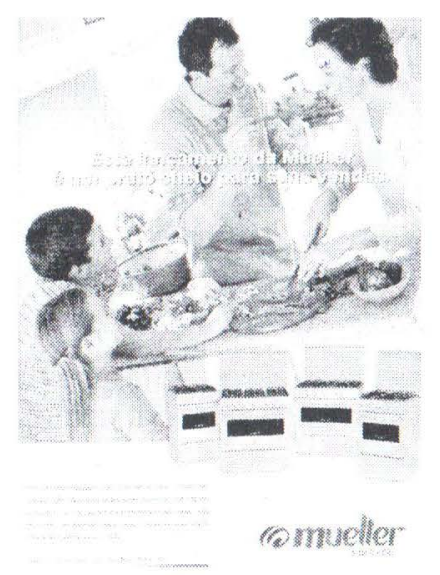

Figura 13

Publicidade e propaganda de fogões mueller (2002)

Fonte: Revista Eletrolar News, ano $3, n^{\circ} 14$, maio/jun. 2002, p. 19

A imagem sugere a cena de uma família - com a "mulher" (mãe) no preparo de alimentos, enquanto o "homem" (pai) e as crianças (filhos) atuam, basicamente, como espectadores do seu trabalho. Diante da questão da relação de gênero na família, cabe observar o problema das influências das atitudes dos adultos nas crianças, em termos da reprodução de conceitos de gênero e modelos relacionais.

Outro exemplo é o da publicidade e propaganda de uma lavadora de roupa da Electrolux, também com foco nas "mulheres", onde se reproduz o padrão tradicional de relação entre "homem" e "mulher". Seu texto principal afirma: "Exatamente do jeito que as mulheres gostam: forte quando elas precisam, gentil quando elas querem"24. Neste caso, o produto encontra-se associado à imagem de um "homem", sugestivamente exposto como um objeto que pode satisfazer as necessidades e desejos das "mulheres". (ver Figura 14)

Bevista Eletrolar News, ano 3, no 14, maio/jun. 2002, p. 19. [sem grifo no original] 


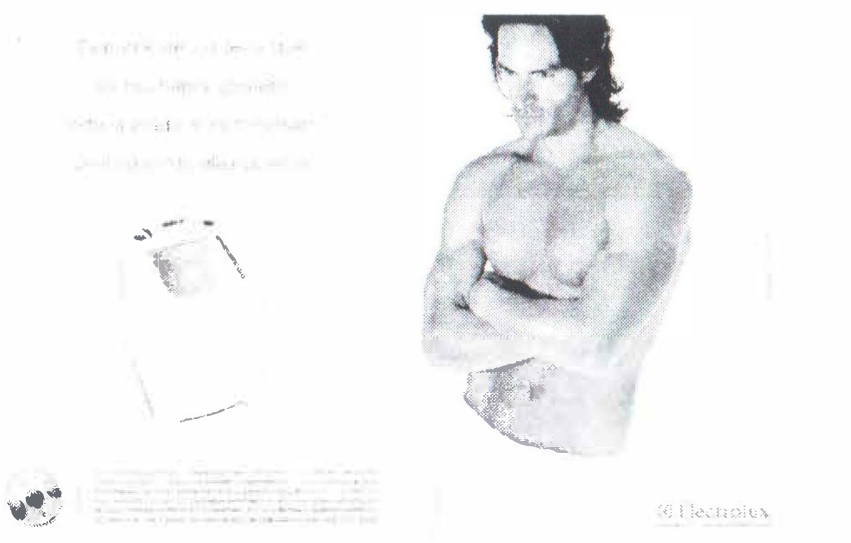

Figura 14

Publicidade e propaganda de lavadora de roupa da electrolux (2002)

Fonte: Revista Eletrolar News, ano 3, $n^{\circ}$ 14, maio/jun. 2002, p. 2-3

Verificam-se casos de publicidade e propaganda de determinados eletrodomésticos, em geral direcionados às mulheres, com foco no público masculino. Entretanto, trata-se de uma comunicação voltada a nichos específicos e muito restritos de mercado. É o caso, por exemplo, de certos modelos de fogões importados, de qualidade e preços bastante superiores em relação à linha de fogões normalmente produzida e comercializada no mercado local, direcionados, segundo relata uma designer da Electrolux do Brasil, aos "homens que cozinham e que, quando o fazem, querem a melhor panela, querem o mellhor fogão..." e que, além disso, são capazes de investir um alto preço nos produtos, comprando, por exemplo, "um fogão que custa, digamos, três, cinco, sete mil reais..." (Cit. In: ONO, 1999, p. 265).

Além disso, há exemplos de publicidade e propaganda que, apesar de utilizarem uma comunicação com imagens e textos relacionados a homens, acabam, indiretamente, reforçando o estereótipo de que o trabalho doméstico "é coisa mais para mulheres". É o caso da publicidade e propaganda de um fogão General Electric, que diz "Novo fogão GE Gourmet Stainless. Resiste ao tempo, aos modismos e aos homens na cozinha"25, sugerindo os fogões têm que ser mais resistentes aos homens do que às mulheres, como se os homens não soubessem usá-los.

Exemplos, como este, ressaltam o problema da exclusão do "homem" na execução do trabalho doméstico, tradicionalmente atribuído à "mulher", ao passo que esta se sobrecarrega de funçōes.

Vale também ressaltar que esta questão de exclusão estende-se também a outros gêneros, considerando-se a pluralidade que os mesmos comportam, diferentemente da noção restrita do binário homem/mulher. 
Não só na publicidade e propaganda, mas também no processo de design de eletrodomésticos - tais como refrigeradores, freezers, fornos, fogões, lavadoras, aspiradores de pó, batedeiras de bolo, liquidificadores, ferros de passar, além de outros - o público-alvo têm sido, em geral, o feminino.

Considerando-se que as sociedades são sempre particularizadas pelas culturas $^{26}$, cabe ressaltar ainda que, tanto a comunicação, quanto os próprios produtos industrializados assumem significados distintos, inclusive no que tange às relações de gênero, de acordo com os diferentes contextos, nos quais se inserem. ${ }^{27}$

As estratégias de comunicação de produtos industrializados têm evidentemente mudado, ao longo da história, incorporando as transformações da sociedade, como demonstram os vários exemplos apresentados neste artigo, que denotam a emergência de novos valores, representações e comportamentos. Verifica-se, no entanto, que o desenvolvimento e a comunicação de grande parte dos eletrodomésticos continuam focados no público feminino, refletindo e promovendo a reprodução de padrões tradicionais de gênero e relações de gênero.

\section{Considerações finais}

$\mathrm{Na}$ história da humanidade, as relações de gênero têm assumido um papel relevante na dinâmica das transformações sociais, culturais, políticas e econômicas.

Ao longo desse processo, novos e variados papéis têm emergido dentre os diferentes gêneros, reforçando-se a necessidade de substituição de sistemas tradicionais outros não-reducionistas, no que concerne à noção de gênero, e mais equilibrados e cooperativos nas relações de gênero que se desenvolvem na sociedade. Vários fatores, no entanto, têm dificultado a dissolução e a substituição de tais sistemas.

Exemplos de pesquisas de mercado, design de produtos, publicidade e propaganda, como os que foram apresentados neste estudo, ilustram práticas voltadas à promoção do consumo de produtos industrializados, fundamentadas no estereótipo do "isto é coisa para mulheres", ou seja, que atribuem às "mulheres" a responsabilidade pelo desempenho de determinados papéis sociais - tais como o trabalho doméstico, por exemplo - considerandoos, por predestinação, "afins" às mesmas. A grande questão é que em nossa sociedade este tipo de trabalho, porque não cria valor, é considerado inferior

26 A cultura é aqui compreendida como as teias de significados tecidos pelo homem nas sociedades, nas quais ele desenvolve sua conduta e sua análise, e através das quais ele dá significado à própria vida, conforme conceito de Geertz (1989; 1996), cuja abordagem teórica distancia-se da visão mecanicista, das verdades absolutas e universais.

27 Não é objetivo, neste artigo, desenvolver este assunto. Salienta-se, no entanto, a importância do desenvolvimento de estudos sobre a questão da diversidade cultural no desenvolvimento e comunicação de produtos industrializados para a sociedade, no que tange às relações de gênero. Para maiores esclarecimentos sobre este assunto, ver: ONO, 1999; 2004; ONO; CARVALHO, 2001; dentre outros. 
ao trabalho realizado na esfera pública e quem o pratica é desvalorizado.

Conseqüentemente, tais práticas têm contribuído para reproduzir valores, padrões e práticas nas esferas da vida pública e privada que revelam relações de gênero dicotômicas, hierárquicas, perversas e excludentes.

Os artefatos participam dos contextos em que vivem as pessoas e constituem uma das referências básicas no contato do indivíduo com o mundo. Refletem e influenciam o desenvolvimento social, cultural, político e econômico, afetando, direta e indiretamente, o bem-estar e a qualidade de vida das pessoas.

A história de produtos industrializados, como a dos eletrodomésticos, traz consigo parte da história das pessoas e das sociedades, às quais estiveram e/ou estão, de algum modo, vinculados. Os hábitos ${ }^{28}$ da vida cotidiana, conforme argumenta Baudrillard (1993), encontram-se estreitamente vinculados aos objetos.

Há, nas diversas sociedades, uma tendência à reprodução de modos de organização, relações e práticas, através de hábitos que se estabelecem ao longo do tempo. Tais hábitos, porém, não são universais, estáticos e imutáveis, mas acompanham as trajetórias dos indivíduos e grupos sociais, existindo sempre a possibilidade de se dissolver tártaros e sedimentações, de se criar e transformar significados, revelando novas formas de relações e ações humanas individuais e coletivas.

Apesar do conceito de gênero e das relações de gênero não se limitarem à esfera da família e ao desenvolvimento do trabalho doméstico, estes refletem e influenciam direta $e$ indiretamente outras instâncias subjetivas e objetivas, implícitas e explícitas, das organizações e práticas dos indivíduos e grupos sociais. Assim, qualquer alteração que se estabelece na esfera da vida privada traz influências à esfera da vida pública, e vice e versa.

Os artefatos desenvolvidos para a sociedade, bem como meios de comunicação de massa, tais como a publicidade e propaganda, por exemplo, atingem um número relativamente grande de pessoas, influenciando a criação, a transformação e a reprodução de valores, padrões de comportamento e práticas na sociedade.

Sob este prisma, salienta-se a importância de uma política de desenvolvimento e comunicação de produtos, voltada à promoção do consumo de produtos industrializados, fundamentada em uma pesquisa contínua e nãoreducionista sobre as funções dos artefatos e suas implicações na vida das pessoas, em seus diversos contextos sociais, culturais, ambientais, econômicos e políticos, dentre outros.

Este artigo não pretende esgotar este assunto, que é amplo e complexo e merece um estudo mais aprofundado, mas sim levantar a questão e trazer uma contribuição aos estudos de gênero e design, considerando-se a sua importância na gestão do desenvolvimento de produtos industrializados que

\footnotetext{
28 Segundo Bourdieu (1983), o conceito de habitus culturais, que caracterizam uma classe ou grupo social, compreende disposições inconscientes, esquemas classificatórios, preferências e gostos por certas práticas e bens culturais. Através dos habitus, os indivíduos incorporam a memória coletiva, conformam suas ações e orientam-se no
} 
companhem a dinâmica das transformações sociais e contribua para um desenvolvimento mais equilibrado das relações de gênero, que depende, dentre outros fatores, da participação cooperativa de pessoas de diferentes gêneros na execução das atividades do cotidiano na sociedade, a partir de uma abordagem não-reducionista que considere a complexidade, pluralidade e variabilidade das relações de gênero.

\section{Referências bibliográficas}

BAUDRILLARD, Jean. 0 sistema dos objetos. Trad. por Zulmira R. Tavares, do original em francês Le système des objets. São Paulo: Perspectiva., 1993.

BOURDIEU, Pierre. Sociologia. Trad. por Paula Montero e Alícia Auzmendi. São Paulo: Ática, 1983. Original em francês.

. Dominação masculina. Rio de Janeiro: Bertrand Brasil, 1999

COELHO NETTO, J. Teixeira. Semiótica. informação e comunicação. São Paulo: Perspectiva, 1980.

DENIS, Rafael. Design, cultura material e o fetichismo dos objetos. Revista Arcos. Design, cultura material e visualidade, volume I, número único, out. 1998, p. 14-39.

DEVINNE, Pamela et al. The American Heritage Dictionary. $2^{\mathrm{a}}$ ed. New York: Houghton Mifflin Company, 1991.

GEERTZ, Clifford. A interpretação das culturas. Rio de Janeiro: LTC - Livros Técnicos e Científicos, 1989.

\section{Los usos de la diversidad. Barcelona: Paidós, 1996.}

LABOURTHE-TOLRA, Philippe e WARNIER, Jean-Pierre. Etnologia - antropologia. Trad. por Anna H. Cavalcanti. Rio de Janeiro: Vozes, 1997. Original em francês Ethnologie - anthropologie.

LARROCHE, Hélène. L'objet industriel. Paris: Centre Georges Pompidou, 1980.

MANZINI, Ezio. A matéria da invenção. Lisboa: Centro Português de Design, 1993.

MOLES, Abraham. Rumos de uma cultura tecnológica. São Paulo: Perspectiva, 1973.

ONO, Maristela Mitsuko. Design industrial e diversidade cultural: um estudo de caso na Electrolux do Brasil S.A. e Multibrás S.A. 1999. 405 p. Dissertação (Mestrado em Tecnologia), Programa de Pós-graduação em Tecnologia, Centro Federal de Educação Tecnológica do Paraná, Curitiba, 1999.

. Design and globalisation: the role of the designer in relation to questions of cultural diversity. Procedures of the Engineering \& Product Design Education Conference 2000, ISBN - 1860582656, Brighton, p. 3-10, set. 2000.

Design industrial e diversidade cultural: sintonia essencial. Estudos de casos nos setores automobilístico, moveleiro e de eletrodomésticos no Brasil. 2004. 1200 p. Tese (Doutorado em Arquitetura e Urbanismo), Faculdade de Arquitetura e Urbanismo, Universidade de São Paulo, São Paulo.

ONO. Maristela M. e CARVALHO, M. G. de. Globalisation and cultural identity: the role of the designer in the local and global contexts. Procedures of the $4^{\text {th }}$ European Academy of Design Conference, ISBN - 972-789-024-5, Aveiro, p. 286-293, abr. 2001.

RABAÇA, Carlos A. e BARBOSA, Gustavo. Dicionário de comunicação. São Paulo: Ática., 1995 
RYBCZYNSKI, Witold. Casa: pequena história de uma idéia. Trad. por Betina Von Staa. Rio de Janeiro/São Paulo: Record, 1999. Original em inglês: Home: a short history of an idea.

SCOTT, Joan. Gênero: uma categoria útil de análise histórica. In: Educação e Bealidade, 20(2) : 71-99, jul./dez. 1995.

TAKEHARA, Akiko. [Palestra] 1986, 28 de agosto. Design - market relationship : consumption and living. Compilação, por Maristela Mitsuko Ono, da palestra proferida no Curso de Industrial Design, na Japan Industrial Design Promotion Organization, por Akiko Takehara, professora da Wako University, Tóquio. Manuscrito.

THÉBAUD, Françoise. Le temps du gender. In: Écrire l'histoire des femmes. Fontenayaux-roses, ENS Éditions Fontenay/Saint-Cloud, Collection Sociétés, Espaces, Temps, 1998, p. 109-161.

\section{Referências de figuras}

Catálogo da AEG, 1997/1998.

Catálogo da Brastemp, fev. 2001.

Revista Claudia, ano 37, $\mathrm{n}^{\circ} 12$, dez. 1998.

Revista Claudia, ano 3, $n^{\circ} 1$, jan. 1999.

Revista Claudia, ano 40, no 10, out. 2001.

Revista Eletrolar News, ano 3, n 14, maio/jun. 2002.

Revista Familia Walita, ano 1, nov. 1955.

Revista Familia Walita, ano 1, $\mathrm{n}^{\circ} 2$, jan. 1956.

Revista Familia Walita, ano 2, $n^{\circ}$ 8, jan./fev. 1957.

Revista Familia Walita, ano 2, n 9, mar./abr. 1957.

Revista Familia Walita, ano 3, $\mathrm{n}^{\circ} 14$, abr./maio/jun. 1958.

Revista Familia Walita, ano 3, $n^{\circ} 15$, jul./ago./set. 1958.

Revista Seleções, 1960. In: TEIXEIRA, Francisco M. P. et al. o futuro sem fronteiras: a história dos primeiros 50 anos da Brasmotor. São Paulo: Prêmio, 1996. 